\title{
PREVALÊNCIA DA INFECÇÃO CHAGÁSICA EM DOADORES DE SANGUE NO TRIÂNGULO MINEIRO.
}

\author{
Hélio Moraes de Souza, César Augusto de Morais e José Roberto Mineo.
}

\begin{abstract}
Os autores analisaram a prevalência da infecção chagásica em 10988 doadores do Servico de Hemoterapia do Hospital Escola da Faculdade de Medicina do Triângulo Mineiro, através de três levantamentos realizados no periodo de dezesseis anos. Observaram queda de prevalência de $16,6 \%$ no primeiro levantamento para $6,9 \%$ no terceiro e predomínio da infecção em negros, no sexo feminino e nas faixas etárias mais avançadas. Discutiram ainda o emprego de medidas profiláticas e o papel do Serviço de Hemoterapia frente ao doador chagásico.

Palavras chaves: Doença de Chagas. Tripanossomiase cruzi. Doença de Chagas transfusional. Violeta de genciana.
\end{abstract}

Desde 1945 quando Dias 4 sugeriu a possibilidade de transmissão da doença de Chagas por transfusão de sangue, $o$ assunto passou a despertar grande interesse. Como conseqüência desenvolveram-se estudos abordando não só a prevalência da infecção tripanossomótica entre doadores de sangue como também analisando aspectos de profilaxia, tratamento do sangue de chagásicos, etc.

Dentre estes trabalhos está o de Jatene e Jácomo 6 que analisa a questão na região onde trabalhamos - Triângulo Mineiro - área endêmica da doença de Chagas. Estes autores, no periodo compreendido entre 1955 e 1959 , observaram que $25 \%$ dos doadores tinham positiva a reação de Guerreiro e Machado. Em seu trabalho analisaram ainda as condutas de seis bancos de sangue da região onde a doença era endêmica e sugeriram que se aplicasse como norma aquela já empregada por dois daqueles serviços: adição de violeta de genciana (V.G.) a todo sangue a ser transfundido, nas regiōes onde a doença de Chagas fosse endêmica.

Em 1968, preocupados com a alta prevalência da infecção chagásica no Banco de Sangue sob nossa responsabilidade (em um dos quais Jatene e Jácomo realizaram seus estudos anteriormente citados) e com o fato de que só podiamos utilizar como meio de diagnóstico o teste de fixação de complemento, decidimos introduzir o uso sistemático da V.G. em todo sangue coletado seguindo a sugestão de Jatene e Jácomo $^{6}$ e a experiência de Rezende ${ }^{9}$ e alicerçados nos trabalhos de Nussenzweig e cols 8 .

Trabalho do Serviço de Hemoterapia e Laboratório Central do Hospital Escola da Faculdade de Medicina Triângulo Mineiro.

Realizado parcialmente com auxílio do Conselho Nacional de Desenvolvimento Científico e Tecnológico (CNPq).

Recebido para publicação em 26/9/1984.
Por outro lado, são ainda preocupantes os índices atuais de prevalência da infecção chagásica em nosso meio como demonstraram Camargo ${ }^{2}$ e Lopes e cols 7 . Apesar do estabelecimento, em 1950, de medidas profiláticas sistematizadas para o extermínio dos triatomineos, e de trabalhos sugerirem que houve realmente diminuição dos índices de prevalência da infecção, estes, em algumas regiões como a nossa, são ainda elevados e questionáveis os motivos para explicá-los.

Diante destes fatos resolvemos analisar a prevalência da infecção chagásica nos doadores do Banco de Sangue do Hospital Escola da Faculdade de Medicina do Triângulo Mineiro com as seguintes finalidades:

1. Analisar o comportamento da prevalência da infecção chagásica em nossos doadores no decorrer dos últimos dezesseis anos;

2. Comparar os resultados com aqueles observados na mesma área geográfica no passado e com os dados atuais relatados nesta e em outras regiões;

3. Questionar sobre as medidas que têm sido utilizadas na profilaxia da transmissão transfusional da tripanossomiase cruzi e que outras condutas poderiam ser empregadas, com maior eficácia;

4. Inquirir e procurar determinar o papel dos Serviços de Hemoterapia frente ao doador chagásico.

\section{MATERIAL E MÉTODOS}

Consta de três levantamentos realizados respectivamente de janeiro de 1967 a junho de 1969 , de janeiro de 1975 a dezembro de 1981 e de janeiro de 1982 a julho de 1983.

Foram avaliados doadores que nestes períodos haviam feito sua primeira doação. Entre eles predo- 
minam parentes dos pacientes internados no Hospital das Clinicas da Faculdade de Medicina do Triângulo Mineiro (hoje Hospital Escola); uma menor parcela é constituida por soldados do Tiro de Guerra e da Polícia Militar. Finalmente, um pequeno contingente é formado por universitários e outros elementos da comunidade. Todos os doadores argüidos sobre suas condições de saúde, negaram qualquer doença no momento da doação. Não apresentavam também ao exame clínico sumário, qualquer anormalidade que os incapacitasse como doadores.

No primeiro levantamento analisou-se somente a prevalência global da infecção chagásica. Já no $2 \%$ e 3 o esta prevalência foi avaliada quanto à raça, sexo e faixa etária.

O diagnóstico da infecção chagásica, no primeiro levantamento, feito em 1755 doadores, baseou-se apenas na positividade da reação de fixação do complemento de Guerreiro e Machado. No segundo levantamento realizado em 7.558 doadores, além desta reação empregou-se também a de imunofluorescência. Foram considerados como portadores da infecção chagásica os doadores que tinham pelo menos uma das duas reações positivas. Finalmente, para o terceiro levantamento que constou de 1.675 novos doadores, tivemos condições de efetuar no sangue dos mesmos, três reações sorológicas: fixação do complemento, imunofluorescência e a de hemaglutinação passiva. Neste terceiro levantamento foram considerados como infectados os individuos que apresentavam também pelo menos uma reação positiva.

Para estudo estatistico empregou-se o teste de diferenças de proporções amostrais com relação à curva normal para se verificar a significância entre os indices de prevalência.

\section{RESULTADOS}

Os resultados obtidos estão expressos nas $\mathrm{Ta}$ belas 1 e 2 e Gráficos 1 e 2 .

Pelo exame da Tabela 1 vê-se que, enquanto no primeiro levantamento a prevalência de infecção foi de $16,6 \%$, no segundo e terceiro caiu para $7,7 \%$ e $6,9 \%$ respectivamente. A análise estatística demonstrou diferença significativa entre os valores obtidos entre 0 primeiro e o segundo levantamento $(Z=3,42)$ e entre $\circ$ primeiro e o terceiro levantamento $(Z=8,85)$. Não houve porém diferença significativa entre os valores do segundo e terceiro levantamentos $(Z=1,14)$.

Tabela 1 - Prevalência da infecção chagásica entre doadores de sangue e análise estatística, nos diferentes levantamentos

\begin{tabular}{|c|c|c|c|}
\hline \multirow{3}{*}{$\begin{array}{ll}\text { Levantamentos } & \text { Doadores } \\
\end{array}$} & \multirow{3}{*}{$\begin{array}{c}\text { No de } \\
\text { doadores }\end{array}$} & \multicolumn{2}{|c|}{ Infectados } \\
\hline & & $N o$ & $\%$ \\
\hline & & & \\
\hline $\begin{array}{c}\text { 10 Levantamento } \\
\text { (janeiro de } 1967 / \text { junho } 1969 \text { ) }\end{array}$ & 1755 & 282 & 16,6 \\
\hline $\begin{array}{l}\text { 2\% Levantamento } \\
\text { (janeiro de 1975/dez. 1981) } \\
\text { 3\% Levantamento }\end{array}$ & 7558 & 582 & 7,7 \\
\hline (janeiro de 1982/julho 1983) & 1675 & 117 & 6,9 \\
\hline Total & 10988 & 981 & 8,93 \\
\hline
\end{tabular}

Análise estatistica

\begin{tabular}{|c|c|}
\hline Comparação & Z Calculado* \\
\hline 1. Levantamento & \\
\hline $\begin{array}{c}\mathrm{X} \\
\text { 2\% Levantamento } \\
\text { 10 Levantamento }\end{array}$ & 3,42 \\
\hline $\begin{array}{l}\text { X } \\
\text { 3\% Levantamento } \\
\text { 2\% Levantamento }\end{array}$ & 8,85 \\
\hline$\frac{X}{\text { 30. Levantamento }}$ & 1,14 \\
\hline
\end{tabular}

* Z crítico (para $\alpha \leq 0,05=1,96$ ) Quando $/ Z$ calculado $/>/ Z$ critico/ $=$ há diferença significativa entre os indices de prevalência. 
Souza HM, Morais CA, Mineo JR. Prevalência da infeção chagásica em doadores de sangue no Triângulo Mineiro. Revista da Sociedade Brasileira de Medicina Tropical 18: 11-16, Jan-Mar, 1985

O Gráfico 1 mostra a prevalência da infecção distribuida segundo o sexo dos doadores estudados no 2\% e 3\% levantamentos. Observou-se no $2 \%$ grupo um significativo aumento da infecção no sexo feminino em relação ao masculino $(Z=-1,97)$, o que não se observa no terceiro $(Z=-0,18)$.

Gráfico 1- Prevalência da infecção chagásica no segundo e terceiro levantamentos distribuidos quanto ao sexo.

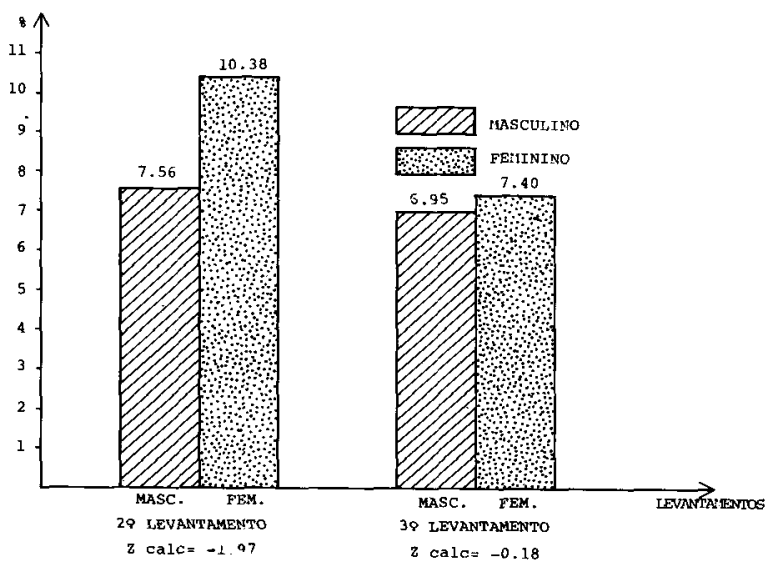

Análise estatística

\begin{tabular}{|c|c|}
\hline \multicolumn{2}{|c|}{$\begin{array}{r}1 \text { - Comparação: Segundo X Terceiro } \\
\text { Levantamentos }\end{array}$} \\
\hline Idade & Z Calculado* \\
\hline $18-20$ & $* 1,53$ \\
\hline $21-25$ & $-1,61$ \\
\hline $25-30$ & 1,51 \\
\hline $31-35$ & 1,86 \\
\hline $36-40$ & 0,21 \\
\hline$>41$ & 1,32 \\
\hline
\end{tabular}

A distribuição dos doadores infectados segundo as faixas etárias foi feita também somente no segundo e terceiro levantamentos. A diferença da prevalência entre os dois levantamentos, para cada faixa etária não foi estatisticamente significante. $\mathrm{Na}$ comparação das faixas de idade, em cada levantamento, observam-se nitidas diferenças, principalmente entre os grupos mais jovens (Gráfico 2 e Análise estatística).

Gráfico 2-Prevalência da infecção chagásica no segundo e terceiro levantamentos distribuidos quanto à idade.

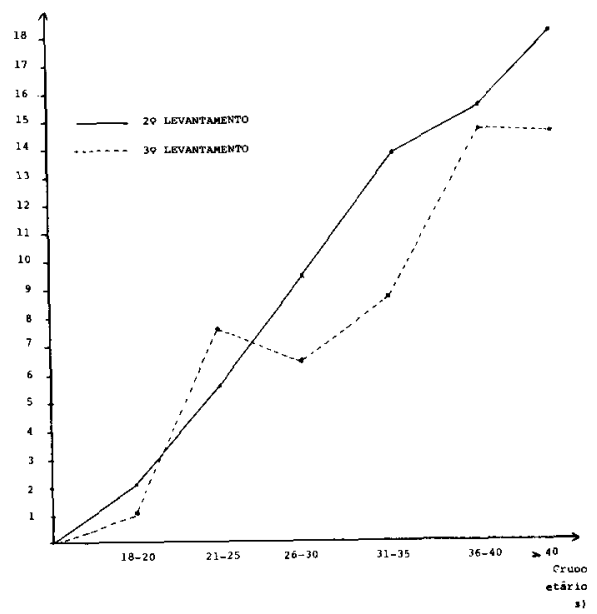

2-Comparação por faixa etária no $20^{\circ}$ e $30^{\circ}$ Levantamentos

\begin{tabular}{|c|c|c|}
\hline \multirow[b]{2}{*}{ Idade } & \multicolumn{2}{|c|}{ Z Calculado } \\
\hline & 2. Levantamento & 3. Levantamento \\
\hline $18-20$ & & \\
\hline$\underset{21-25}{X}$ & $-6,06$ & $-4,99$ \\
\hline $21-25$ & & \\
\hline$\underset{26-30}{X}$ & $-4,08$ & 0,58 \\
\hline $26-30$ & & \\
\hline$\underset{31-35}{X}$ & $-2,9$ & $-0,87$ \\
\hline $31-35$ & & \\
\hline $\begin{array}{c}X \\
36-40 \\
36-40\end{array}$ & $-0,77$ & $-1,69$ \\
\hline $\begin{array}{c}X \\
>41\end{array}$ & $-0,89$ & 0,29 \\
\hline
\end{tabular}


Finalmente, a Tabela 2 agrupando os dois últimos levantamentos, mostra a prevalência de infecção nas raças branca, negra e mestiça, observando um aumento significativo da incidência na raça negra em relação à branca $(Z=-3,51)$ e em relação à mestiça $(Z=-2,16)$. A diferença encontrada entre as raças branca e mestiça não foi estatisticamente significativa $(Z=-0,45)$.

Tabela 2-Prevalência da infecção chagásica nos dois últimos levantamentos distribuidos quanto à raça.

\begin{tabular}{lrrr}
\hline Daçd Doadores & No de doadores & \multicolumn{2}{c}{ Infectados } \\
& & \multicolumn{1}{c}{ N. } & \multicolumn{1}{c}{$\%$} \\
\hline Branca & & 495 & 7,15 \\
Mestiça & 6921 & 85 & 7,52 \\
Negra & 1130 & 119 & 10,07 \\
Total & 1182 & 699 & 7,57 \\
\hline
\end{tabular}

Comparação

$$
\begin{aligned}
& \text { Branca x Mestiça } \\
& \text { Branca X Negra } \\
& \mathrm{Z} \text { calculado }=0,45 \\
& \text { Mestiça } x \text { Negra } \\
& \mathrm{Z} \text { calculado }=3,51 \\
& \mathrm{Z} \text { calculado }=2,16
\end{aligned}
$$

\section{DISCUSSĀO}

Observamos uma evidente queda da prevalência da infecção chagásica em nosso Serviço nos últimos dezesseis anos.

Considerando que os nossos atuais doadores são provenientes do mesmo grupo sócio-econômico daqueles do primeiro e segundo levantamentos e dos analisados por Jatene e Jácomo entre 1955 e 1957, somos levados a concluir que esta queda se deve em grande parte às medidas profiláticas desenvolvidas na região a partir de 1950.

Tal afirmativa é reforçada pelo aumento da prevalência, no último levantamento, de $8,6 \%$ na faixa etária dos 31 aos 35 anos para 14,6\% entre os 36 e 40 anos, correspondendo essa última a individuos nascido 5 a 9 anos antes do início das campanhas de erradicação da tripanossomíase. Raciocínio similar é válido para a faixa dos 31 a 35 anos no segundo levantamento.
Os nossos dados estão de acordo com os levantamentos epidemiológicos efetuados em nosso meio (R.H. Fabre: comunicação pessoal, 1984) e mesmo em outras regiōes 1012 , demonstrando uma nítida regressão da infecção chagásica nos grupos etários mais jovens.

A diferença da prevalência entre as faixas etárias dos 18 a 20 e 21 a 25 anos, nos dois últimos levantamentos, é também nítida e significativa e devese provavelmente, ao fato de serem estes doadores, na sua grande maioria, soldados do Tiro de Guerra Local, os quais, além da sua predominante procedência urbana, são de nivel sócio-econômico bastante superios à média dos demais doadores do Serviço.

A maior freqüência de reações positivas no sexo feminino certamente se deve ao fato de ser um grupo mais homogêneo, ao contrário dos doadores masculinos que, além de familiares dos pacientes internados, como a quase totalidade das mulheres, são constituídos também por soldados e alguns elementos da comunidade de classe sócio-econômica mais elevada.

O significativo aumento da prevalência da infeç̧ão chagásica na raça negra pode se dever às mais precárias condições sócio-econômicas deste grupo étnico.

$O$ fato de que a prevalência da doença de Chagas mostra evidente declinio, com um baixo índice de infecção entre indivíduos de baixa idade, evidenciando que a transmissão natural da doença faria caminhar para um controle definitivo, tem obrigado a todos nós dirigirmos nossa atenção para a via transfusional de transmissão, já extensivamente analisada 13411.

Entendemos portanto quê medidas profiláticas seguras devam ser rigorosamente observadás e para tanto a Comissão Nacional de Hemoterapia do Ministério da Saúde, em sua resolução no 01/75 preconiza:

1. Triagem sorológica rotineira dos doadores com exclusão daqueles com positivos;

2. Adição, a todo sangue doado, de substância tripanossomicida, como a violeta de genciana quando a triagem sorológica não puder ser feita.

Com relação ao primeiro item entendemos que a simples obrigatoriedade da realização da reação sorológica não resolve o problema. Sabemos que reações sorológicas seguras dependem de um grande número 
de variáveis que pequenos serviços de hemoterapia e/ou laboratórios não conseguem controlar, possibilitando a liberação para uso de sangue contaminado.

Quanto ao emprego de substâncias tripanossomicidas, "do que se conhece até o momento, parece realmente ser a violeta de genciana a mais indicada.

Apesar de seu efeito tripanossomicida satisfatoriamente demonstrado, a sua cor tem limitado em muito a sua utilização. De nossa parte, podemos afirmar que temos empregado este corante em nosso Serviço desde 1968, com boa aceitação por parte de médicos e pacientes, não observamos até o momento nenhum caso de doença de Chagas transfusional nestes últimos dezesseis anos e nem reações adversas importantes que pudessem ser imputadas à violeta de genciana.

Com o desenvolvimento da hemoterapia e uso cada vez maior dos hemoderivados, necessário se faz estudar, mais detalhadamente, a ação deste sal sobre os diversos componentes sangüíneos. Entendemos entretando, que em pequenas comunidades, o seu emprego é uma grande e segura arma contra esta forma de propagação da doença descrita por Carlos Chagas.

Outro aspecto que consideramos relevante e creditamos como da responsabilidade dos serviços de hemoterapia, diz respeito ao destino dos doadores com sorologia positiva. Considerando ser este um individuo em sua plena força de trabalho e assintomático, uma vez que não apresentou queixas que o incapacitasse como doador, necessário se faz definir uma conduta, segura, ética e coerente para com o doador chagásico.

\section{SUMMARY}

The prevalence of Trypanosoma cruzi infection among 10988 blood donors is analysed after three surveys done during the last 16 years at the Hemotherapy Service of the Hospital Escola da Faculdade de Medicina do Triangulo Mineiro. The 16.6\% prevalence in the first survey fell to $6.9 \%$ in the last. The infection was more common in negro females and the elderly. The prophylaxis of blood transfusiontransmitted Chagas disease is discussed, as well as what measures should be taken by the Blood Banks when infected donors are discovered.

Key words: Chagas' disease. Trypanosomiasis cruzi. Blood transfusion transmission. Gentian violet.

\section{AGRADECIMENTOS}

Aos professores Edison Reis Lopes e Antônio Carlos de Oliveira Menezes pelas sugestões e às Srtas. Heloisa das Graças de Sousa, Jucélia Ribeiro Torres e Sra. Heloisa Vieira Cabariti pelo registro dos casos e datilografia do texto.

\section{REFERÊNCIAS BIBLIOGRÁFICAS}

1. Amato Neto V. Transmissão da doença de Chagas por transfusão de sangue. Clínica e Terapêutica 6: 208-213, 1977.

2. Camargo ME. Doença de Chagas: inquérito sorológico nacional. In: XIII Congresso da Sociedade Brasileira de Medicina Tropical e II Congresso da Sociedade Brasileira, Brasília, 1977.

3. Cerisola JA, Rabinovich A, Alvarez A, Corleto CA, Prunedi J. Enfermedad de Chagas y la transfusion de sangre. Boletin de la Oficina Sanitária Panamericana 73: 203-221, 1972.

4. Dias E. Um ensaio de profilaxia da moléstia de Chagas. Imprensa Nacional, Rio de Janeiro, 1945.

5. Dias JCP, Dias RB. Aspectos sociais da doença de Chagas. Revista Goiana de Medicina 25: 257-268, 1979.

6. Jatene AD, Jácomo R. Doença de Chagas e transfusão de sangue. Revista Goiana de Medicina 5: 23-30, 1959.

7. Lopes ER, Morais CA, Chapadeiro E, Mineo JR, Leite LC, Guimarães AHB, Rocha A, Gava M. Prevalência da Infecção Chagásica em necrópsias no Triângulo Mineiro. In: Resumos do XX Congresso da Sociedade Brasileira de Medicina Tropical, Salvador, p. 26, 1984.

8. Nussenzweig V, Sonntag R, Biancalana A, Pedreira de Freitas JL, Amato Neto V, Kloetzel J. Ação da Violeta de Genciana sobre o Tripanossoma cruzi in vitro; sua importância na esterilidade do sangue destinado à transfusão. Revista Paulista de Medicina 42: 57-58, 1953.

9. Rezende JM. Problema da transmissão da doença de Chagas por transfusão de sangue; emprego da Violeta de Genciana como medida profilática. Revista Goiana de Medicina 11:35-47, 1965.

10. Rocha e Silva EO. In: Brener Z, Andrade Z (ed) Trypanosoma cruzi e Doença de Chagas, Guanabara-Koogan, Rio de Janeiro, 1979.

11. Sherlock IA. Profilaxia da doença de Chagas. Revista Brasileira de Malariologia e Doenças Tropicais 31: 121 $135,1979$.

12. Vichi FL, Costa JC, Mauad Neto M, Romero LC. Declinio da prevalência da moléstia de Chagas em Ribeirăo Preto (SP). Estudo epidemiológico. Arquivos Brasileiros de Cardiologia 34: 347-349, 1980. 